\title{
A Himalayan dental adventure!
}

Please send any ideas for feature articles for consideration to:

Rowena Milan,

British Dental Journal,

The Macmillan Building,

4-6 Crinan Street

London

N1 9XW

Email: r.milan@nature.com

Shekha Bhuva, a Periodontology MClinDent specialist trainee from Guy's Dental Hospital, was lucky enough to take part in a once-in-a-lifetime trip to Nepal as a volunteer dentist. Here she talks about her experiences.

I had been looking for a volunteer dental project for some time before coming across 'SmileHigh', a charity founded by London-based orthodontist Julian Haszard and Nepalese dentist Mingma Sherpa. Julian, a keen mountaineer, realised there was a great need for dental care whilst in the Himalayas on a climbing expedition in 2003. He decided to take action and since 2004, has led several successful dental missions to the Everest region.

The latest trip involved visiting a remote village set high in the Himalayas. It promised to be the most ambitious so far and sounded like just the adventure I was after!

The mission was made possible by, and run in conjunction with, the United Nations World Food Program (UNWFP), headed by Richard Ragan. They planned to deliver 11 months worth of rice and lentils to a deprived village named Samagon in remote Nepal. Their initiative involved encouraging the local people to work to improve their own village in exchange for regular nutritious food - a great example of empowering people to help themselves.

We reached the village of Samagon in a Russian Mi17 UN helicopter (Fig. 1) which allowed us breathtaking views of the Himalayas. Despite early concerns from the pilot about unpredictable weather, the helicopter landed safely in the middle of a nearby field. Many villagers came out to greet us and helped us bring our equipment into a local lodge which would act as home and work place for the next ten days.

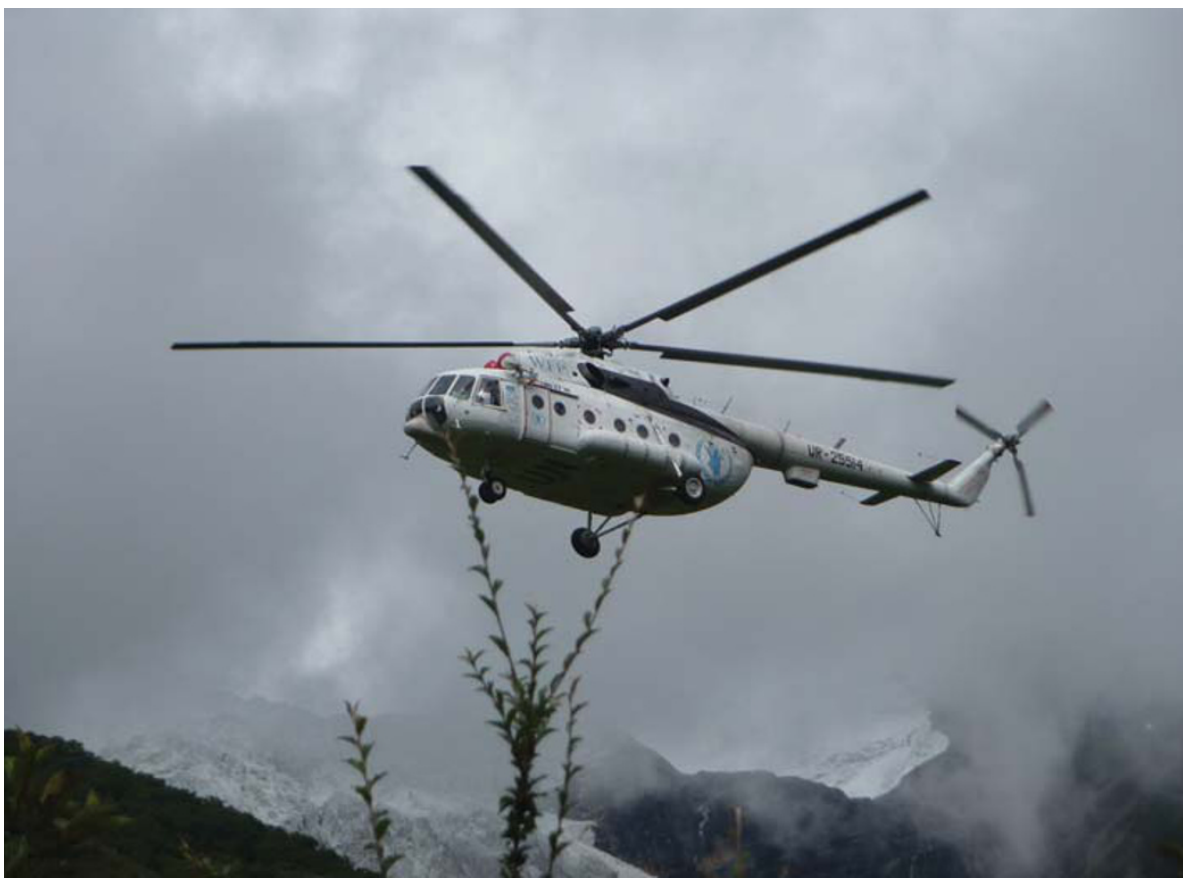

Fig. 1 Our helicopter journey into Samagon (photo courtesy of Mike Scott, Taranaki Daily News)

\section{The village of Samagon}

Samagon is nestled in the Nubri valley (3,800 $\mathrm{m}$ above sea level), overlooked by the magnificent beauty of Mount Manaslu (Fig. 2), the world's eighth highest mountain at $8,163 \mathrm{~m}$. It has been called the Forgotten Kingdom, not only because of its geographically isolated location but also because until 1992 there was a complete government restriction on foreigners entering the area. There are no roads leading into the area - the closest road to Kathmandu, Nepal's capital city, is a six-day hike away.

The population is approximately 600 and people were of Tibetan ancestry. It was obvious despite this beautiful, idyllic backdrop that life here was incredibly tough, with 90\% of villagers living in absolute poverty. It is hard to imagine how people survive day to day life. Village elders estimated the infant mortality rate to be close to $30 \%$. There are no shops, let alone medical or dental services. In the case of illness, it was common to call for the local lama (spiritual teacher) and the treatment offered would be in the form of prayers and chants. This could not be further from our scientific evidence-based approach!

Housing in Samagon is simple, with one wood and brick room acting as 
lounge, kitchen and bedroom for a whole family. There is limited electricity in most homes, and an indoor fire doubled as central heating and stove. Food is scarce, with the diet consisting of mainly potatoes, rice, a few lentils and occasionally yak meat.

There is little in the way of trade into or from this village. For many years, people have exchanged local wood for food produce at the Tibet border, which is a three to four day trek on foot. However, in recent years, there has been a government enforced ban on the timber trade to try to prevent deforestation putting even more pressure on locals' ability to afford food.

\section{Getting down to business}

After a day of acclimatising to the altitude, work began in earnest. Our first aim was to introduce ourselves to the locals and begin the task of education. This was done by holding an oral hygiene demonstration in the local school (Fig. 3). It was a shock to see how basic the school grounds were. The two classrooms were open aired and stonewalled. I was instantly struck by these bright, inquisitive children, all keen to talk to us. Despite their unkempt appearance, they all wore big smiles and laughed and played. I was completely taken by their spirit and the whole team was keen to do what we could to help.

Due to the absolute lack of amenities, all equipment had to be flown with us. We had a comprehensive array of equipment including elevators and forceps, two handpieces, capsulated GIC and an amalgamator, a portable autoclave and hundreds of toothbrushes and tubes of toothpaste. It was important to remember the nondental equipment like cups, disinfecting wipes etc. Organising this was in itself a big task and was the culmination of many kind and generous donations.

We designated three clinical areas within our lodge. After being triaged by a Nepali dentist, patients were sent to either the restorative or oral surgery area. The restorative area was indoors, consisting of two beds. Electricity only ran at certain hours, so we had to make special provisions to run our two handpieces and a head light proved an invaluable aid (Fig. 4). Here GIC was used to

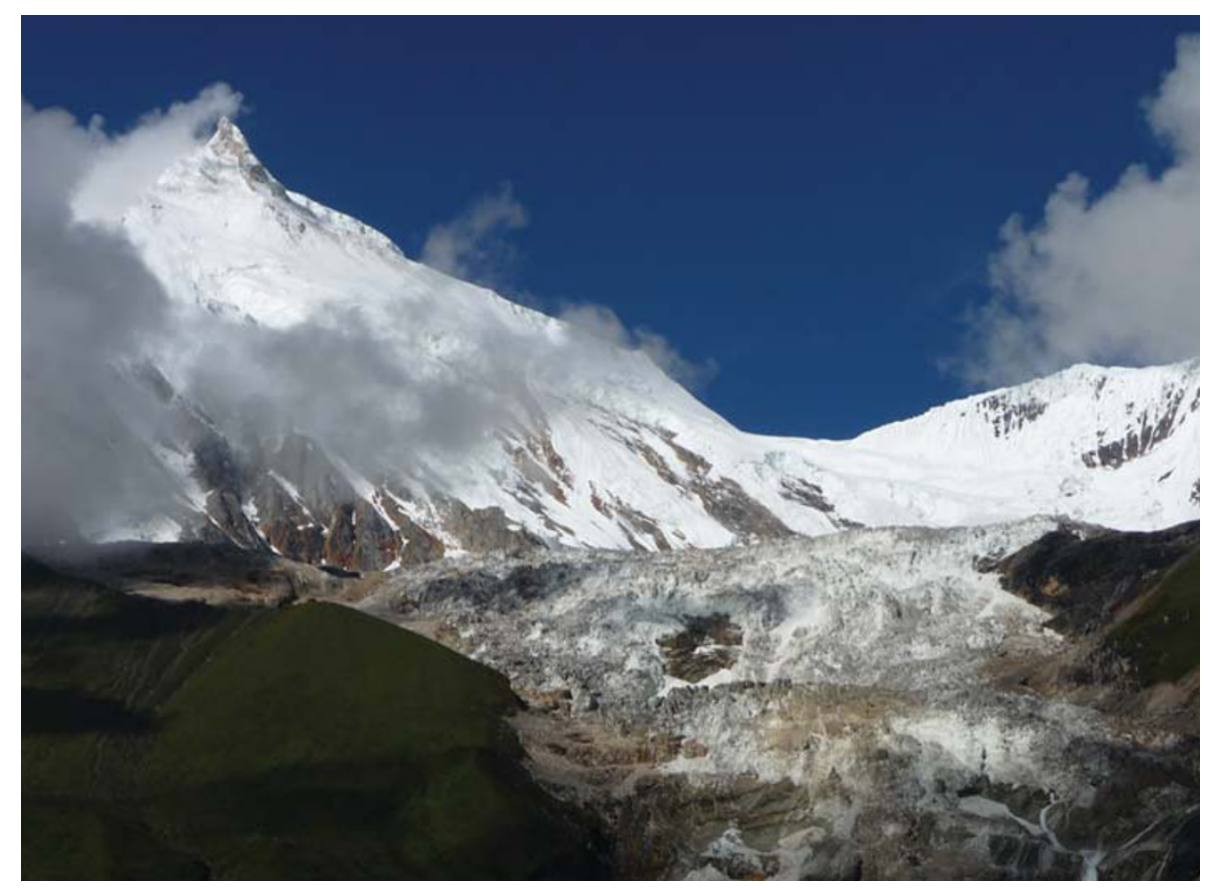

Fig. 2 View of Mt Manaslu as seen from the village

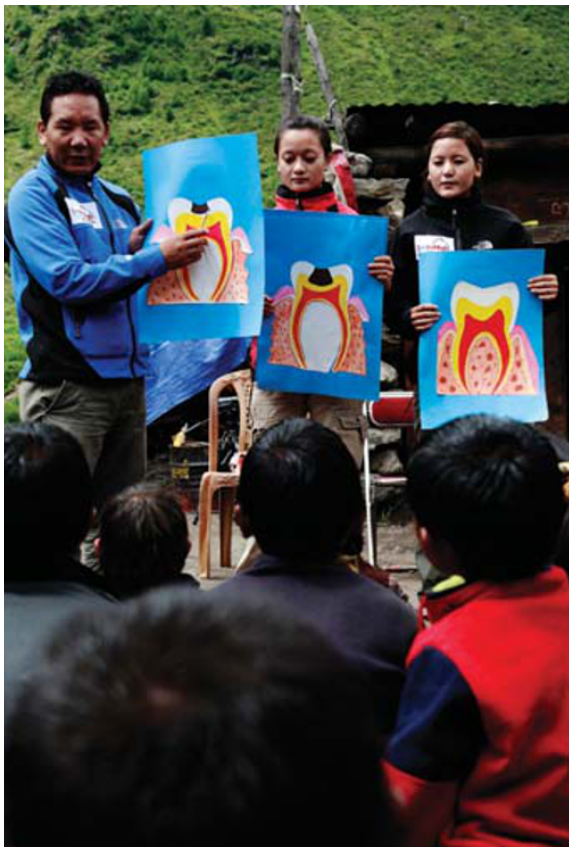

Fig. 3 Our oral hygiene presentation at the local school (photo courtesy of Mike Scott, Taranaki Daily News)

fill restorable cavities, although the periodontist in me meant I couldn't help but get my scalers out too!

Any teeth presenting with gross caries, irreversible pulpitis or abscesses were extracted. These extractions were carried out in a separate area to ensure that the other patients, never exposed previously to dental treatment, did not panic. It also helped to keep the restorative and triage areas clean.

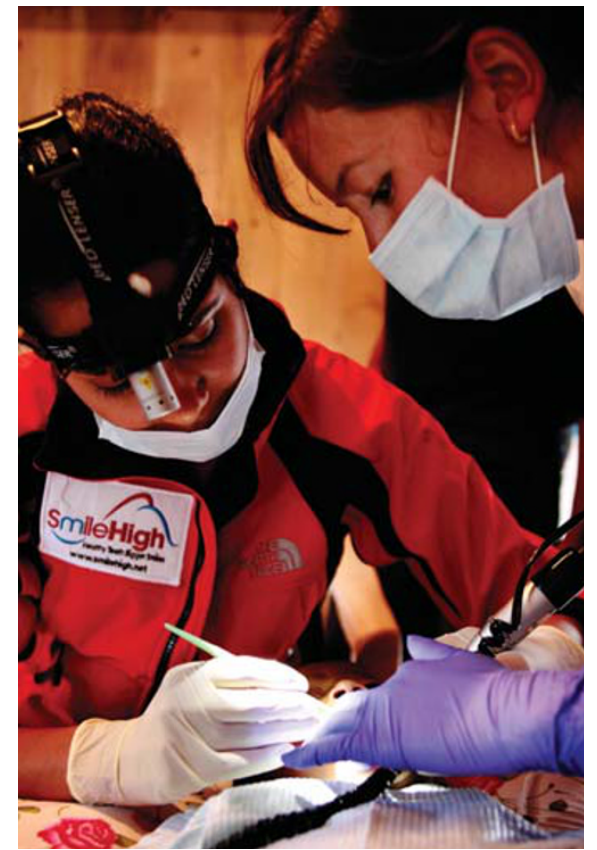

Fig. 4 Shekha carrying out restorative work in a makeshift clinic (photo courtesy of Mike Scott, Taranaki Daily News)

As well as providing dental care and education and giving oral health demonstrations in Samagon, it was important to us to get the message out to surrounding villages that a dental and medical team were in the area. So, after seeing all the children and adults in the village, we welcomed monks from nearby monasteries and also people from other villages. We were humbled to hear that some people walked for half a day to reach us. 


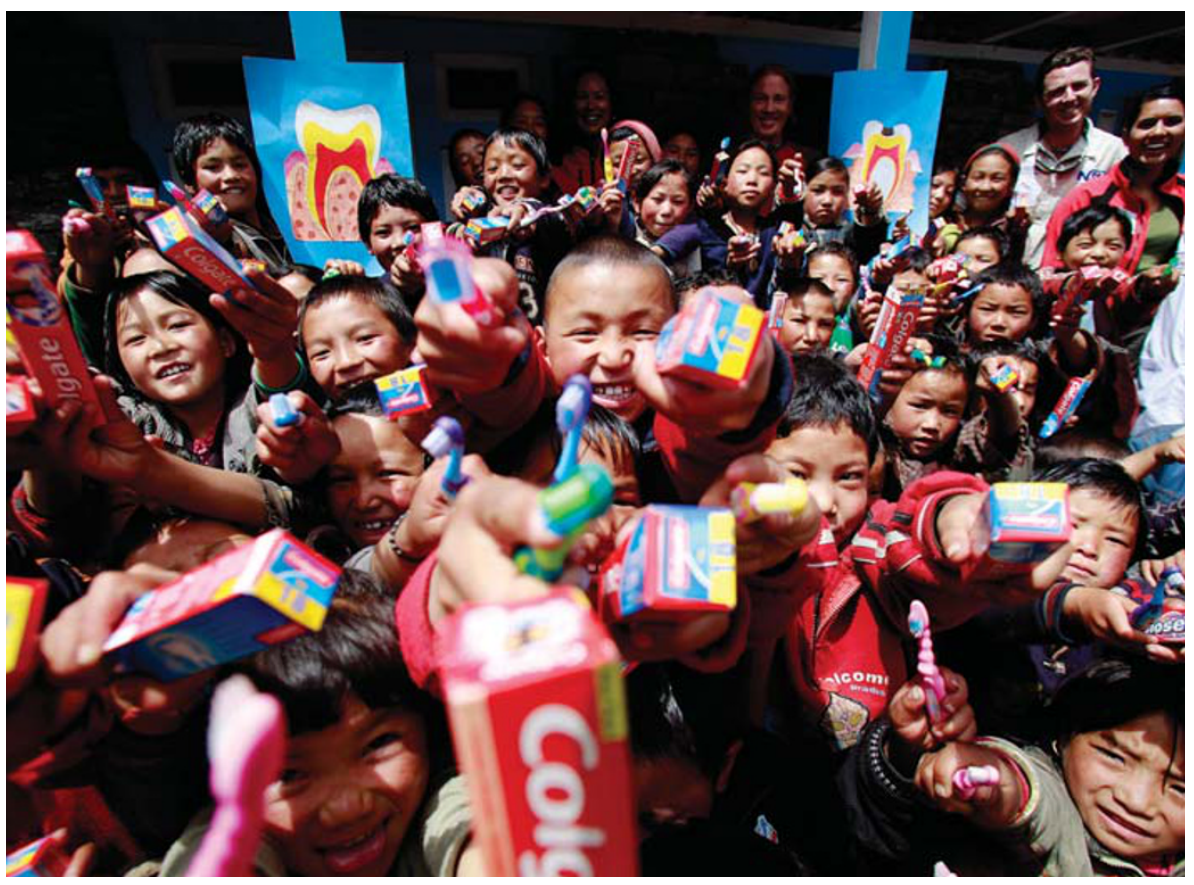

Fig. 5 The local children delighted to receive free toothpaste and toothbrushes (photo courtesy of Mike Scott, Taranaki Daily News)

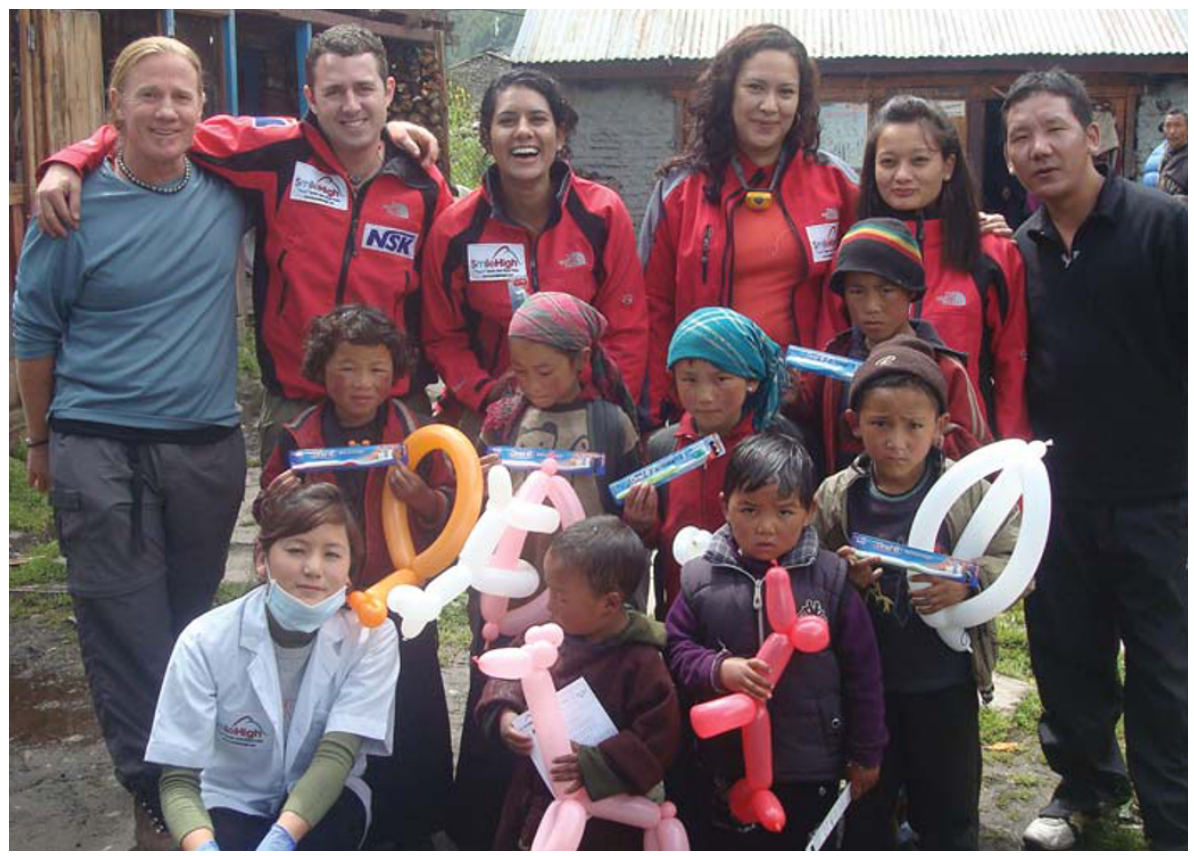

Fig. 6 Our team of five international dentists (Shekha standing third from the left) and two SmileHigh hygienists

\section{Need for more help}

The vast majority of patients had never seen a dentist before, so seeing us with all our gear must have been intimidating. Most patients let us get on with any necessary treatment without fuss and were so appreciative for our help.

Due to the isolated location of Samagon, the local diet contained few refined sugars in the form of fizzy drinks, sweets or chocolates. However, everyone drank vast quantities of very sugary tea throughout the day and there were minimal oral hygiene measures. Although a few children had healthy teeth, most had unmet dental needs such as caries and periodontal disease. A large number presented with abscesses and a history of pain for many years, and you could literally see their relief once the offending tooth had been extracted.

In total we examined approximately 650 patients, placed over 250 fillings and extracted 350 teeth. At least 700 toothbrushes and tubes of toothpaste were distributed (Fig. 5). A great initiative by one of the dentists was to make balloon animals for all the children - I could not count how many we made or how many smiles they brought! I feel our most important role was educating people to prevent dental disease. However, this is a message that requires constant reinforcement and resources.

There was a clear message from the village that more help is needed in the area. Aside from basic dental and medical needs, there was a great need for women's healthcare and family planning, as childbirth is still associated with a high mortality rate.

\section{Our team}

Our team of dentists came from all corners of the globe, ranging from Los Angeles to Cambodia! I could not have asked for better people to work with. The camaraderie was fantastic and I feel I have come away with some great friends (Fig. 6).

I feel fortunate that as dentists we have the skills to help those less fortunate in a unique way. A small gesture has the potential to make a big impact on someone's quality of life. Leaving behind the luxuries of 'normal' life for just a week really made me appreciate how much we take for granted and how many services we have at our fingertips.

This was a completely humbling and satisfying experience, full of adventure, breathtaking natural beauty, spirited local people and clinicians with a passion for humanitarian work. The work of SmileHigh is inspirational and I look forward to watching this project flourish and continue to provide a vital lifeline in rural Nepal.

A massive thank you goes to all those who supported us through this mission: Braun Oral B, Colgate, Dentsply, Henry Schein, NSK, GC, GKT Dental School, Girish and Jay Bhuva, and Leverstock Green Dental Practice. Thanks to the UN WFP (Nepal), SmileHigh and Russell Brice (Himex) for making me feel so welcome. The hard work carried out by both teams to improve the quality of life for people through sustainable dental and medical care, as well as vital food provisions in remote Nepal is inspirational. I am also indebted to Mike Scott (Taranaki Daily News) for capturing the place and the emotion.

Shekha is currently enrolled on the part time Periodontology MClinDent specialist training program at Guy's Hospital and is working parttime in Cuffley and Hemel Hempstead in practice limited to periodontology. For more information please email Shekha at shekha.bhuva@googlemail. com or visit www.smilehigh.net. 